\title{
Regression Model to Estimate Standard Time through Energy Consumption of Workers in Manual Assembly Lines under Moderate Workload
}

\author{
Abdul Ayabar, ${ }^{1}$ Jorge De la Riva, ${ }^{2}$ Jaime Sanchez, ${ }^{2}$ and Cesar Balderrama ${ }^{3}$ \\ ${ }^{1}$ Department of Industrial Engineering, Instituto Tecnológico de Delicias, Paseo Tecnológico Km 3.5, 33000 Delicias, CHIH, Mexico \\ ${ }^{2}$ Division of Postgraduate Studies and Research, Instituto Tecnológico de Ciudad Juárez, Avenida Tecnológico 1340, \\ 32500 Ciudad Juárez, CHIH, Mexico \\ ${ }^{3}$ Department of Industrial and Manufacturing Engineering, Universidad Autónoma de Ciudad Juárez, Avenida del Charro 450 Norte, \\ 32310 Ciudad Juárez, CHIH, Mexico
}

Correspondence should be addressed to Abdul Ayabar; d97540250@itcj.edu.mx

Received 19 September 2014; Accepted 31 January 2015

Academic Editor: Uğur Özcan

Copyright (C) 2015 Abdul Ayabar et al. This is an open access article distributed under the Creative Commons Attribution License, which permits unrestricted use, distribution, and reproduction in any medium, provided the original work is properly cited.

\begin{abstract}
We propose a Standard Time (ST) Estimate Model based on energy demand to attain more equal work distribution in manual assembly lines. The proposal was developed estimating the energy consumption by monitoring the heart rate (HR) of 84 people between 18 and 48 years old while performing repetitive activities under moderate workload (2.5-5.0 kilocalories/minute $(\mathrm{Kcal} / \mathrm{min})$ ). Variables on one model were determined, which were based on energy consumption (EC) using the 13-variable Best-Subset function. Subsequently, a general equation for the Standard Time (ST) Estimate Model was calculated through lineal regression. Two significant variables were obtained: total kilocalories (Kcal tot.)/pieces and total Kcal/operation time (OT) for each station, which are included in a Standard Time Estimate Model. ST can be represented with a regression model measuring the total number of kilocalories consumed by workers and the OT, which can help companies to balance the cycle time in their assembly lines.
\end{abstract}

\section{Introduction}

Leibovich et al. [1] argued that work overload during manual operations in industry entails issues such as excessive physical work, insufficient rest, inadequate work conditions, monotony, work stress, and poor social relations, as well as instability and perception of work insecurity in regard to attitudes to work. Satisfaction, change expectations, wellbeing, work commitment, and exhaustion are very common risk characteristics in the manufacture industrial sector. Iridiastadi and Nussbaum [2] said that the long work days increase muscle fatigue resulting in worker's low performance and productivity.

According to Meza and Ramírez et al. [3], this is why the number of complaints associated with physical fatigue in manufacture industry workers has been increased due to the intensification of work performed throughout the working day. Steven et al. [4] concluded that impact of this issue in terms of loss of productivity, illness, and detriment on the standard of living is with no doubt enormous, and cannot be determined accurately. Krause et al.s research [5] shows that a higher EC at work is linked to an accelerated progression of atherosclerosis, even after the cardiovascular risk factors have been controlled. This appeared particularly among older workers and those with preexistent ischemic cardiomyopathy or carotid artery stenosis conditions.

Ricci et al. [6] discovered that $40 \%$ of workers are fatigued and such problem represents 136.4 thousand million dollars in loss of productivity every year (100 thousand million more than in not fatigued workers). $84 \%$ of costs are more associated with a poor performance at work than with those commonly related to absenteeism.

Not much has been done to reduce the workload in regard to energy consumed by workers when a production line is balanced, the classification on proposed assembly line balance issues, from Ghosh and Gagnon [7] and Scholl 
TABLE 1: Physical characteristics of each industry subject.

\begin{tabular}{|c|c|c|c|c|c|c|c|c|c|c|}
\hline & Gender & $\begin{array}{l}\text { Number of } \\
\text { participants }\end{array}$ & & $\begin{array}{c}\text { Weight } \\
\text { (Kg) }\end{array}$ & $\begin{array}{l}\text { Height } \\
(\mathrm{cm})\end{array}$ & $\begin{array}{c}\text { Age } \\
\text { (years) }\end{array}$ & $\begin{array}{l}\text { Phys. } \\
\text { cond. } \\
\text { (1-10). }\end{array}$ & $\begin{array}{c}\text { Exp. } \\
\text { (years) }\end{array}$ & \multicolumn{2}{|c|}{ Smoker } \\
\hline & & & & (Average) & (Average) & (Average) & (Average) & (Average) & Yes & No \\
\hline \multirow{4}{*}{ Line 1} & Men & 50 & & 83 & 177.5 & 26.1 & 3.4 & 3.93 & 25 & 25 \\
\hline & Women & N/A & & N/A & N/A & N/A & N/A & N/A & N/A & $\mathrm{N} / \mathrm{A}$ \\
\hline & Total & 50 & Media & 83 & 177.5 & 26.1 & 3.4 & 3.93 & & \\
\hline & & & S.D. & 10.12 & 6.86 & 3.92 & 0.8 & 4.35 & & \\
\hline \multirow{4}{*}{ Line 2} & Men & 4 & & 70 & 162 & 22 & 3 & 0.5 & 0 & 4 \\
\hline & Women & 12 & & 61.7 & 158 & 21.7 & 3 & 1.56 & 8 & 4 \\
\hline & Total & 16 & Media & 65.83 & 160 & 21.83 & 3 & 1.02 & & \\
\hline & & & S.D. & 5.28 & 2.46 & 1.52 & 0.73 & 0.6 & & \\
\hline \multirow{5}{*}{ Line 3} & Men & 15 & & 67.8 & 177 & 27.8 & 4.8 & 1.9 & 0 & 15 \\
\hline & Women & 3 & & 57 & 168 & 25 & 4 & 3 & 0 & 3 \\
\hline & Total & 18 & Media & 62.4 & 172.4 & 26.4 & 4.44 & 2.45 & & \\
\hline & & & S.D. & 5.41 & 4.95 & 8.58 & 1.28 & 1.09 & & \\
\hline & Total & 84 & & & & & & & & \\
\hline
\end{tabular}

Note: Suunto Team Manager Physical Condition Scale.

and Becker's [8] literature, has been revised and they are simply intended to reduce time, work stations, and available spaces. A study performed by Fallentin et al. [9], where physical workload regulations and outlines are evaluated from a Nordic perspective, has also been analyzed and it is concluded that such knowledge or documentation on current laws or regulations to reduce the muscle skeletal disorders caused by work is limited.

The comparison on energy consumption in workloads is grounded on the study performed for Bink [10] that proposes an acceptable limit of energy consumption of $5.33 \mathrm{Kcal} / \mathrm{min}$ in men and $4.0 \mathrm{Kcal} / \mathrm{min}$ in women in an 8 -hour workday. This number corresponds to a $1 / 3$ of the maximum energy consumption of the average man in the USA [10]. Ayoub and Mital [11] state that during an 8-hour workday, the energy consumption must be an average lower than $5.0 \mathrm{Kcal} / \mathrm{min}$ for men and $3.55 \mathrm{Kcal} / \mathrm{min}$ for women. These values correspond to a $33 \%$ of the maximum aerobic power for men and women, respectively.

Studies made by Groover [12] have shown an existing linear function between the variables of oxygen consumption, the HR, and the EC. The HR is specifically based on the increase of blood supply required for physical work and that can be utilized to estimate the EC. A variety of devices are currently being used to determine the consumed kilocalories through the HR, such as the case of the Suunto Team Pod equipment. Their estimation method is centered in the relation of the cardiorespiratory function and the EC measure, where the accuracy of the EC estimation method relies on sophisticated mathematics methods, including neuronal networks, signal processing, component analysis, and diffuse systems developed for Firstbeat Technologies Ltd. [13].

Manufacture industry usually cares more for time and efficiency ignoring energy consumption in their parameters, as a crucial variable to determine workloads in workstations. For this reason, it is imperative to create a regression model that estimates the ST based on the EC of each workstation in order to balance the worker's energy load by considering their physical characteristics.
TABLE 2: Latin charts by work line in industry.

(a)

\begin{tabular}{llllll}
\hline Line 1 & \multicolumn{5}{c}{ Day } \\
& 1 & 2 & 3 & 4 & 5 \\
\hline Subject 1 & C & B & A & D & E \\
Subject 2 & E & D & C & B & A \\
Subject 3 & D & A & B & E & C \\
Subject 4 & A & E & D & C & B \\
Subject 5 & B & C & E & A & D \\
\hline
\end{tabular}

$\mathrm{A}=$ distribution, $\mathrm{B}=$ framing number $1, \mathrm{C}=$ framing number $2, \mathrm{D}=$ visual, and $\mathrm{E}=$ packing.

(b)

\begin{tabular}{lllll}
\hline Line 2 & & & Day & \\
& 1 & 2 & 3 & 4 \\
\hline Subject 1 & B & D & A & C \\
Subject 2 & D & B & C & A \\
Subject 3 & C & A & B & D \\
Subject 4 & A & C & D & B \\
\hline
\end{tabular}

$\mathrm{A}=$ polished, $\mathrm{B}=$ visual, $\mathrm{C}=$ injection, and $\mathrm{D}=$ cable.

(c)

\begin{tabular}{llcl}
\hline Line 3 & \multicolumn{3}{c}{ Day } \\
& 1 & 2 & 3 \\
\hline Subject 1 & B & A & C \\
Subject 2 & A & C & B \\
Subject 3 & C & B & A \\
\hline
\end{tabular}

$\mathrm{A}=$ assembly number $1, \mathrm{~B}=$ assembly number 2 , and $\mathrm{C}=$ assembly number 3.

\section{Methods}

2.1. Participants. Three production lines were studied having as a requirement the inclusion of a repetitive and moderate load activity to be performed from $2.5 \mathrm{Kcal} / \mathrm{min}$ to $5.0 \mathrm{Kcal} / \mathrm{min}$. Production lines 1, 2, and 3 comprised 5, 4, and 3 workstations, respectively. Physical characteristics of all workers involved were first registered, as shown in Table 1. 
TABLe 3: Data collection in industry.

\begin{tabular}{|c|c|c|c|c|c|c|c|c|}
\hline & OT & Kcal tot. & Kcal act. & Pieces & $\begin{array}{c}\text { Kcal } \\
\text { tot./piece }\end{array}$ & $\begin{array}{c}\text { Kcal } \\
\text { act./pieces }\end{array}$ & $\begin{array}{c}\text { Kcal } \\
\text { tot./OT }\end{array}$ & $\begin{array}{c}\text { Kcal } \\
\text { act./OT }\end{array}$ \\
\hline \multicolumn{9}{|l|}{ Line 1} \\
\hline Mean & 496 & 1838.11 & 861.24 & 55.80 & 32.90 & 15.28 & 3.70 & 1.73 \\
\hline Deviation & 25.43 & 385.45 & 343.71 & 4.40 & 6.20 & 5.76 & 0.73 & 0.68 \\
\hline \multicolumn{9}{|l|}{ Line 2} \\
\hline Mean & 306.25 & 1163.97 & 323.96 & 91.75 & 12.68 & 3.51 & 3.80 & 1.06 \\
\hline Deviation & 6.71 & 300.82 & 254.04 & 4.52 & 3.15 & 2.68 & 1.00 & 0.84 \\
\hline \multicolumn{9}{|l|}{ Line 3} \\
\hline Mean & 42.57 & 1774.81 & 672.29 & 583.33 & 3.05 & 1.15 & 41.90 & 15.88 \\
\hline Deviation & 2.99 & 526.97 & 433.67 & 48.51 & 0.90 & 0.72 & 12.92 & 10.48 \\
\hline
\end{tabular}

Note: Kcal total includes metabolic and digestive kilocalories in workday. Pieces represent the number produced during the activity day.

2.2. Design of Latin Charts. Upon completion of physical and personal characteristics, a design of Latin charts was created by work line as shown in Table 2 . To avoid noise generation in design, workstations were randomly selected by weekdays worked and workstations.

2.3. Data Collection. The energy consumption was obtained through the HR. This was monitored with the Suunto equipment for the EC estimate. Such equipment was previously validated by Weippert et al. [14] and it is demonstrated to be virtually similar to an electrocardiogram device based on the R\&R testing, hence, its accuracy in regard to $H R$ measurements. Additionally, the equipment was verified under oxygen consumption testing and EC by Montgomery et al. [15], proving to be a reliable device for EC measurement through the HR. It was also evidenced to be an adequate metabolic consumption estimator through the HR on both gender individuals aged 20 to 71 years. Balderrama et al. [16] used $t$ par tests; it is shown to have a performance similar to that obtained by direct measurements.

2.4. Statistical Analysis. All statistical processes used the MiniTab 16 Program. Once the monitoring was completed, the variables to be analyzed with the Best-Subset function were selected in order to choose the best options for the model, which were gender, weight, height, age, physical condition, experience, smoker, total kilocalories, activity kilocalories, total/pieces kilocalories, activity/pieces kilocalories, total/OT kilocalories, and activity/OT kilocalories. Considering the preceding study, a regression analysis was carried out later with the minimum number of variables which resulted in a high degree of multiple determination coefficient $\left(R^{2}\right)$ and the estimated standard error.

\section{Results}

Kilocalories estimated by the Suunto equipment were monitored every day to complete the Latin chart. A total of 84 sets of data were collected as shown in Table 3.

3.1. Variable Selection. Variable data were analyzed to identify which one would be significant in the model, considering the time of operation as a variable of response. Table 4 shows outcomes resulting from the MiniTab 16 Program.

Considering the results shown in Table 4, each regression model was evaluated utilizing objective diagnosis such as the multiple determination coefficient $\left(R^{2}\right)$ and the estimated standard error $(s)$. One two-variable option with multiple determination coefficient of 94.1 was selected, since the higher degree option with the lower number of variables must be statistically chosen. Besides, there only exists a slight difference of 3.7 between the selected and the best rate with an estimated standard error of 45.119, which is acceptable.

Once the variables to be utilized were selected, an analysis of multiple linear regression was initiated with the MiniTab 16 Program to estimate the model and the variable's coefficients. The resulting model (a) meets the Anderson-Darling residual standard test offering a $P$ value of 0.991 , which is shown as follows:

$$
\mathrm{ST}=232+8.29 \mathrm{Kcal} \text { tot. } / \text { pieces }-4.76 \mathrm{Kcal} \text { tot. } / \mathrm{OT} \text {. }
$$

\section{Discussion}

The time estimate and line balance techniques focus on time and space reduction but they do not consider the EC. This results in an accumulated consumption since the workloads in stations could be considerably high, which means that they exceed the recommended limits. This issue causes fatigue in workers, Bink [10], who should be allowed to recuperate. In order for the body to eliminate fatigue, authors such as Farrer et al. [17] consider how important it is not to exceed half of the aerobic capacity that compromises the metabolism. In consequence, it is necessary to design activities below such consumption. An energy balance of workers must be found in the production lines without sacrificing line efficiency. Otherwise, it could result in low productivity, absenteeism, and shift rotation.

Based on additional studies realized by Ilmarinen [18], the workday should not exceed $50 \%$ of the maximum VO2, considering the possibility of having breaks. Assuming that such breaks were not allowed, the maximum VO2 should not exceed 33\%. Astrand [19] has emphasized to not exceed 50\%, to avoid stress effects in large muscle groups, since exceeding this percentage reduces body weight, heart rate cannot reach 


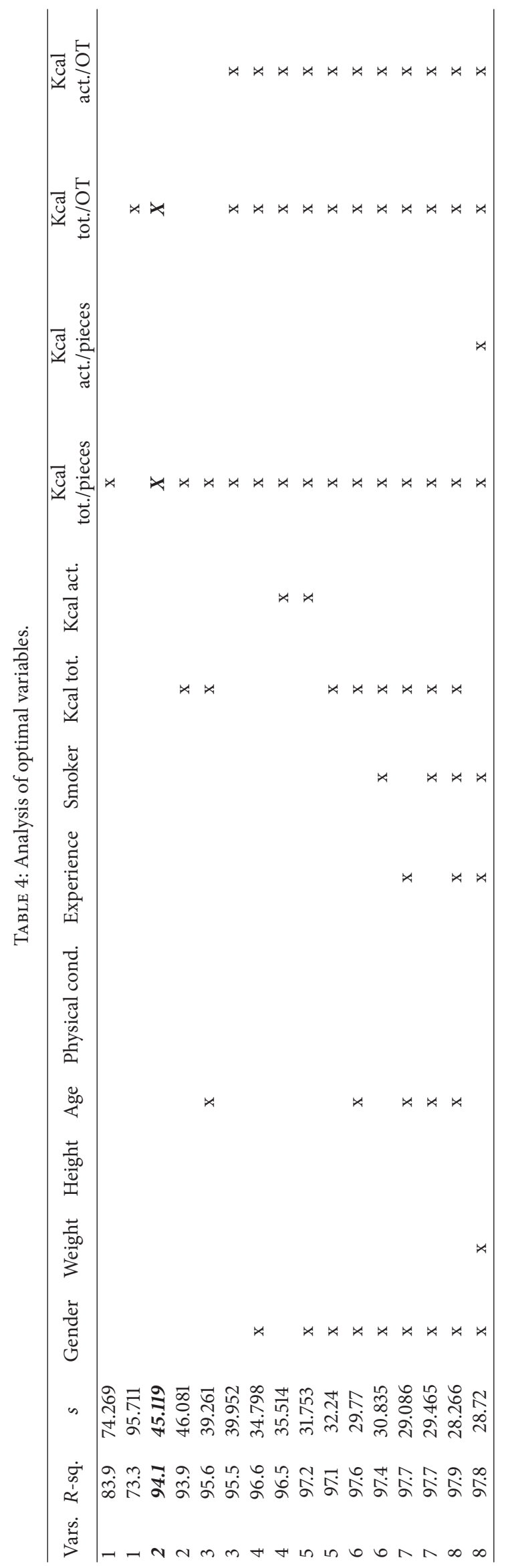


a standard condition, and the subjective uncomfortableness increases throughout the day.

A fatigued individual can more easily fail his work duties that can range from a poor quality in product performance to hurting himself or having an accident due to distractions caused by lack of attention. This implies a cost increase due to work days missed and product reworking.

This model can determine the consumption of total energy consumed in a workday if we consider the OT equal to the line cycle time. In accordance with previous studies, it is suggested that consumed energy should not exceed $33 \%$ of the total energy consumed daily for no longer than 8 hours work, Bink [10]. Additional research by Jörgersen [20] establishes $30-35 \%$ of aerobic effort for combined physical work including material handling operations.

Manufacture industry will be benefited with the creation of methodology aimed at designing or rebalancing a production line that includes the proposed model, which will be considered as a basis to determine the workload for each station. With this, an energetic balance to maintain and increase the quality and productivity rates will be achieved.

In addition, this study could generate a design of predetermined time based on energy consumption that approaches the situation of human consumption during a workday. Since time predetermined methods were designed for some physical characteristics of a qualified worker, nowadays numerous physiological variations of workers exist.

\section{Conclusion}

As conclusion for this study, the possibility of creating a regression model to estimate the ST of a work station based on the workers EC that could be utilized in production lines with repetitive and moderate load activities has been demonstrated. The result of this model could be compared to the workstation OT or the cycle time, and determine if it is energetically loaded or otherwise, offers discharge activities aimed to balance the station ST by observing the production line cycle time and keeping simultaneously an EC balance of each station.

\section{Conflict of Interests}

The authors declare that there is no conflict of interests regarding the publication of this paper.

\section{References}

[1] F. Leibovich, R. Injoque, and M. Schufer, "Evaluación de la inestabilidad laboral como estresor psicosocial en el trabajo," Anuario de Investigaciones, vol. 15, 2008, http://www.scielo.org .ar/scielo.php?script=sci_arttext\&pid=S1851-16862008000100029\&lng=es\&nrm $=$ iso.

[2] H. Iridiastadi and M. A. Nussbaum, "Muscular fatigue and endurance during intermittent static efforts: effects of contraction level, duty cycle, and cycle time," Human Factors, vol. 48, no. 4, pp. 710-720, 2006.

[3] P. Meza and A. Ramírez, Investigación sobre la determinación de fatiga física en trabajadoras de la industria textil del norte de Sinaloa [Ph.D. thesis], Instituto Tecnológico de los Mochis, 2004.

[4] S. Steven, M. Lawrence, H. Joseph, L. Lennart, and J. MagerStellman, "Factores psicosociales y de organización," in Enciclopedia de salud y seguridad en el trabajo, p. 34, Ministerio de Trabajo y Asuntos Sociales, Madrid, Spain, 1998.

[5] N. Krause, R. J. Brand, G. A. Kaplan et al., "Occupational physical activity, energy expenditure and 11-year progression of carotid atherosclerosis," Scandinavian Journal of Work, Environment and Health, vol. 33, no. 6, pp. 405-424, 2007.

[6] J. A. Ricci, E. Chee, A. L. Lorandeau, and J. Berger, "Fatigue in the U.S. workforce: prevalence and implications for lost productive work time," Journal of Occupational and Environmental Medicine, vol. 49, no. 1, pp. 1-10, 2007.

[7] S. Ghosh and R. J. Gagnon, "Comprehensive literature review and analysis of the design, balancing and scheduling of assembly systems," International Journal of Production Research, vol. 27, no. 4, pp. 637-670, 1989.

[8] A. Scholl and C. Becker, "State-of-the-art exact and heuristic solution procedures for simple assembly line balancing," European Journal of Operational Research, vol. 168, no. 3, pp. 666693, 2006.

[9] N. Fallentin, E. Vikari-Juntura, M. Waersted, and A. Kilbom, "Evaluation of physical workload standards and guideline from a nodic perspective," Scandinavian Journal of Work, Environment \& Health, vol. 27, supplement 2, pp. 1-52, 2001.

[10] B. Bink, "The physical working capacity in relation to working time and age," Ergonomics, vol. 5, no. 1, pp. 25-28, 1962.

[11] M. Ayoub and A. Mital, Manual Materials Handling, Taylor \& Francis, London, UK, 1989.

[12] M. Groover, Work Systems and the Methods, Measurement, and Managment of Work, Pearson Prentice Hall, Upper Saddle River, NJ, USA, 1st edition, 2007.

[13] Firstbeat Technologies, An Energy Expenditure Estimation Method Based on Heart Rate Measurement, Firstbeat Technologies, Jyväskylä, Finland, 2012.

[14] M. Weippert, M. Kumar, S. Kreuzfeld, D. Arndt, A. Rieger, and R. Stoll, "Comparison of three mobile devices for measuring $\mathrm{R}-\mathrm{R}$ intervals and heart rate variability: polar S810i, Suunto t6 and an ambulatory ECG system," European Journal of Applied Physiology, vol. 109, no. 4, pp. 779-786, 2010.

[15] P. G. Montgomery, D. J. Green, N. Etxebarria, D. B. Pyne, P. U. Saunders, and C. L. Minahan, "Validation of heart rate monitorbased predictions of oxygen uptake and energy expenditure," Journal of Strength and Conditioning Research, vol. 23, no. 5, pp. 1489-1495, 2009.

[16] C. Balderrama, G. Ibarra, J. De La Riva, and S. López, "Evaluation of three methodologies to estimate the $\mathrm{VO}_{2 \max }$ in people of different ages," Applied Ergonomics, vol. 42, no. 1, pp. 162-168, 2010.

[17] F. Farrer, G. Minaya, J. Niño, and M. Ruiz, Manual de Ergonomía, Fundación MAPFRE, 2nd edition, 1997.

[18] J. Ilmarinen, "Physical requirements associated with the work of aging workers in the European Union," Experimental Aging Research, vol. 28, no. 1, pp. 7-10, 2002.

[19] P.-O. Astrand, "Human physical fitness with special reference to sex and age," in International Research in Sports and Physical Education, pp. 517-558, Charles C. Thomas, Springfield, Ill, USA, 1964.

[20] K. Jörgersen, "Permissible loads based on energy expenditure measurements," Ergonomics, vol. 28, no. 1, pp. 365-369, 1985. 

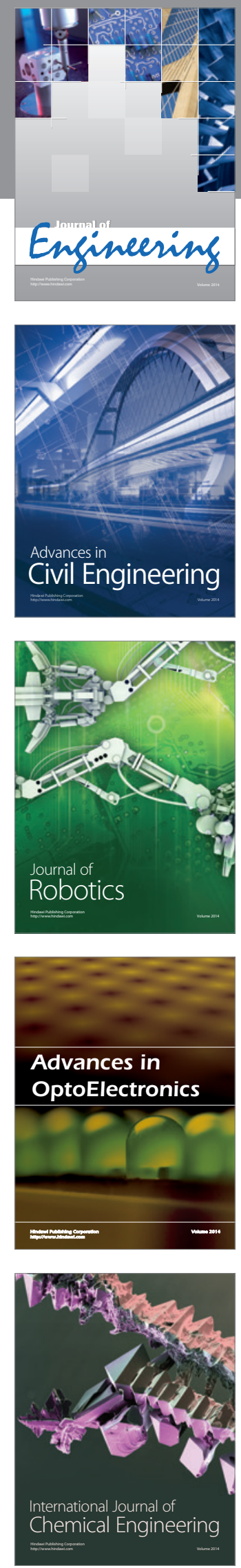

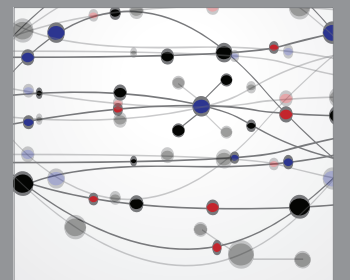

The Scientific World Journal
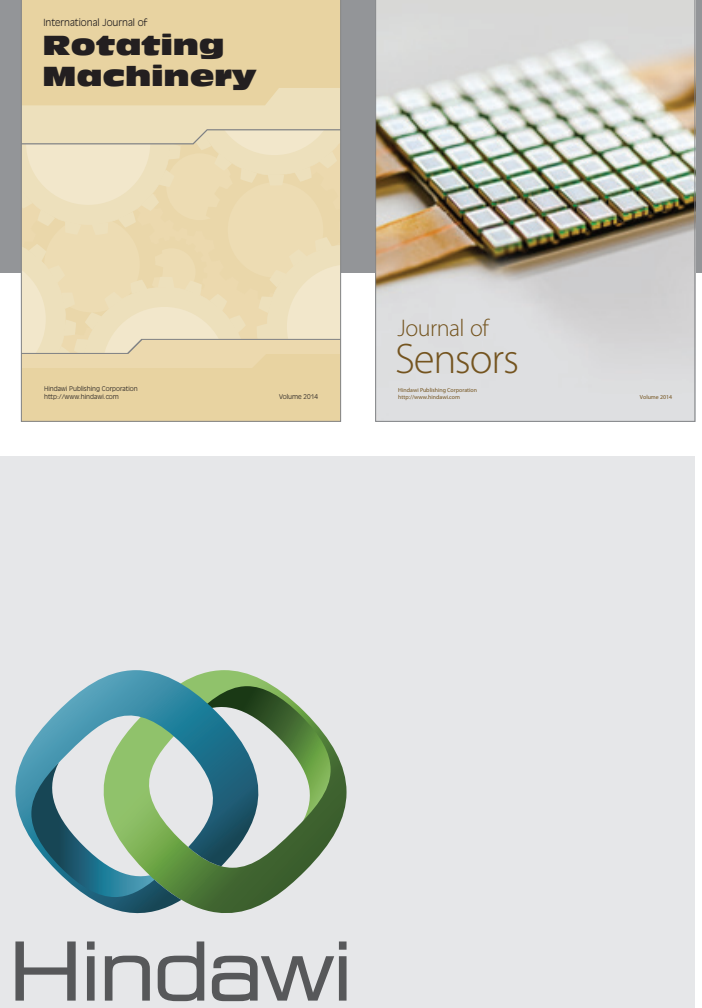

Submit your manuscripts at http://www.hindawi.com
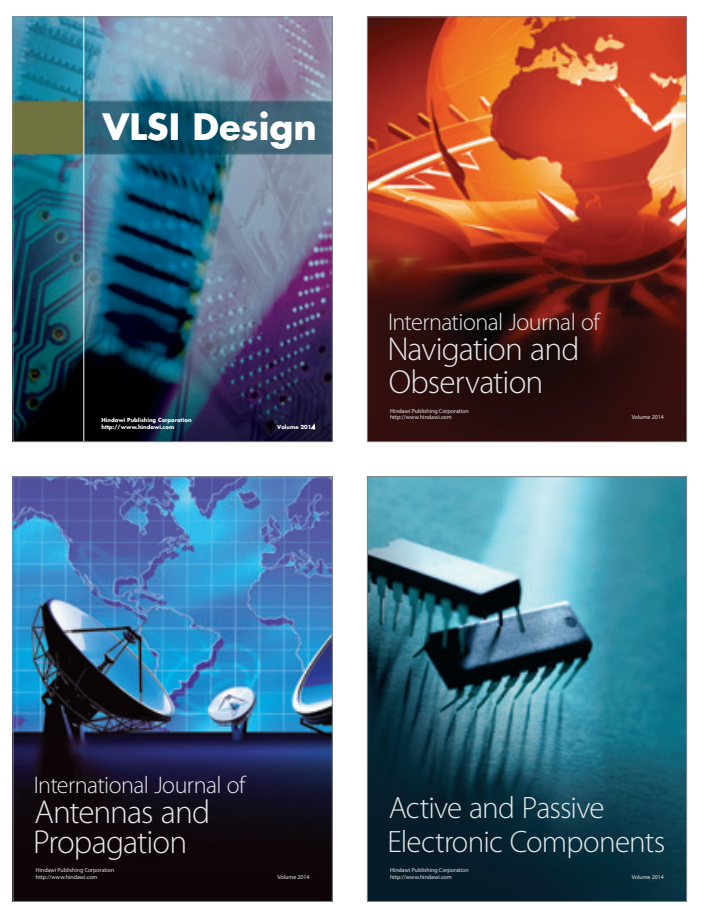
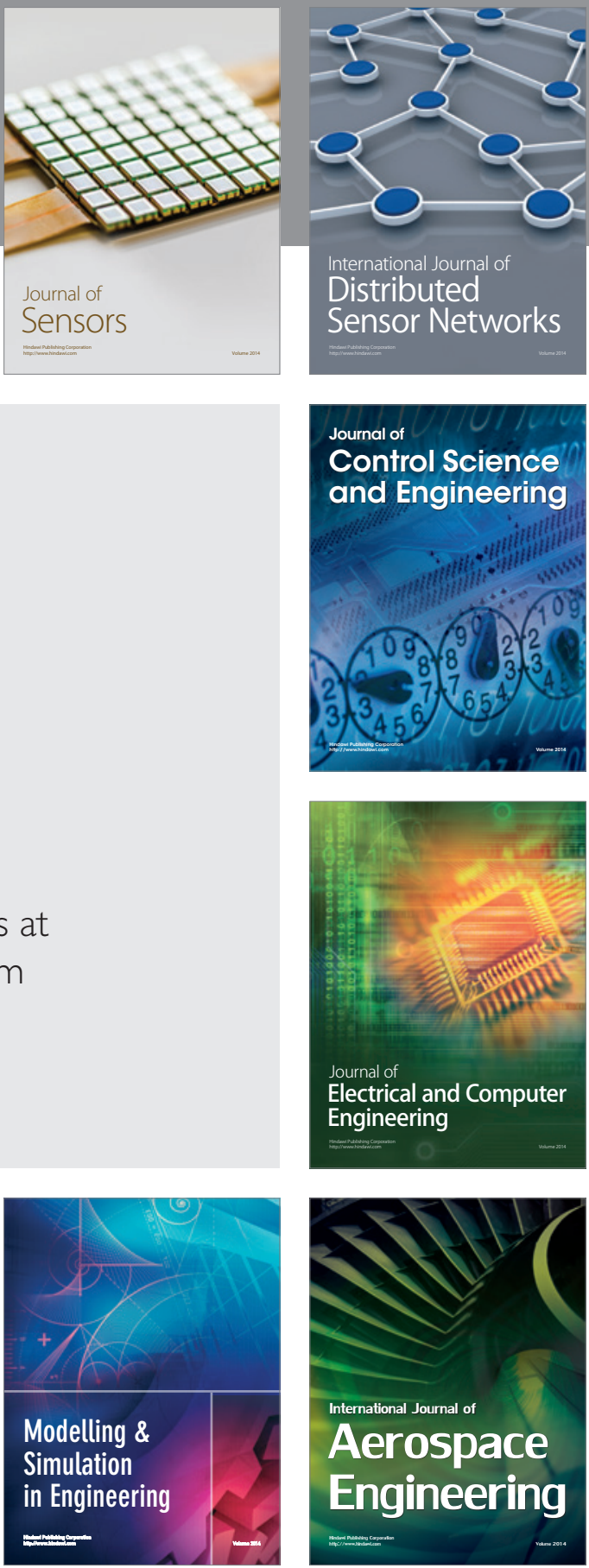

Journal of

Control Science

and Engineering
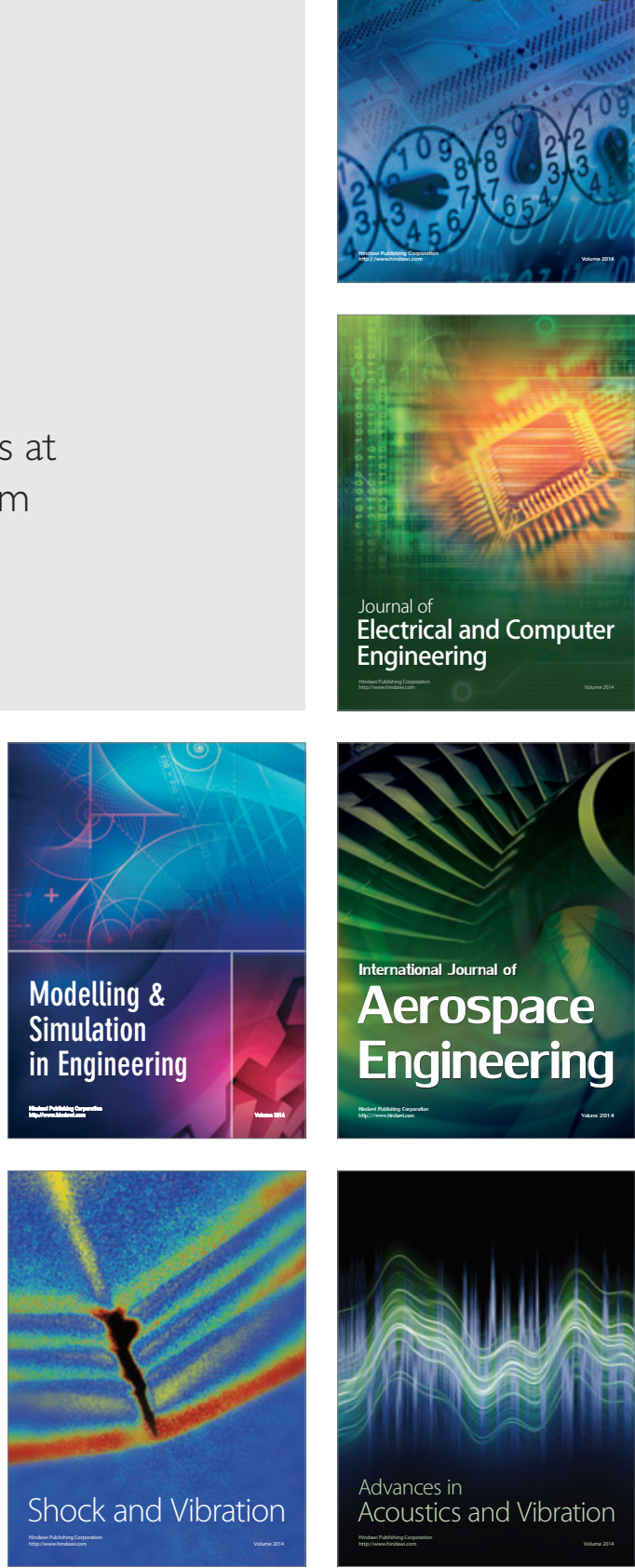